\title{
Driving forces for agroforestry uptake in Mediterranean Europe: application of the Analytic Network Process
}

\author{
Marko Lovric ${ }^{1}$, Mercedes Rois-Díaz ${ }^{1,2}$, Michael den Herder ${ }^{1}$, Andrea Pisanelli ${ }^{3}$, Natasha Lovric ${ }^{1}$, Paul J. \\ Burgess $^{4}$ \\ ${ }^{1}$ European Forest Institute, Finland \\ ${ }^{2}$ University of Santiago de Compostela, Spain \\ ${ }^{3}$ Consiglio Nazionale delle Ricerche, Italy \\ ${ }^{4}$ Cranfield University, Cranfield, Bedfordshire, MK43 OAL, UK
}

\begin{abstract}
The factors that determine the implementation of four alternative agroforestry practices or no agroforestry on a theoretical 200 ha farm in Mediterranean Europe were examined using an Analytic Network Process (ANP) model. The four agroforestry practices considered were implementation of a form of i) high natural and cultural value agroforestry, ii) agroforestry with high value trees, and agroforestry for iii) arable and iv) livestock systems. The ANP model was developed in a participatory manner through a systematic series of quantitative questionnaires and workshops with agroforestry researchers. In general, all the Mediterranean agroforestry systems were associated with high benefits and opportunities, but also with high costs and high risks. The greatest benefits were attributed to high natural and cultural value agroforestry systems, which greatly contributed to the highest priority of this system. Overall ranking of priorities for the agroforestry management alternatives show robustness in the sensitivity analysis. The "no agroforestry" land use became the preferred option when costs were given a weighting of 0.50 or greater.
\end{abstract}

Keywords: Multiple criteria decision analysis (MCDA), Analytic network process (ANP), Mediterranean, drivers

\section{Introduction}

Agroforestry has been a common land use practice in Europe since early civilization. However since the industrial revolution it has often been replaced by intensive monoculture agriculture or forestry. Since the 1990s, agroforestry has been drawing increasing attention as a sustainable land use practice and there have been European initiatives to support and promote its uptake (Smith 2010; Burgess et al., 2015). Nevertheless, although there are successful examples, the uptake of new agroforestry practices has been limited (Pisanelli et al. 2014; Luske et al. 2016). The decision of farmers on whether to implement agroforestry on their farms depends on many socio-economic and environmental factors (Camilli et al. 2017, Garcia de Jalón et al. 2017, Rois-Díaz et al. 2017).

In Europe, the greatest extent of agroforestry occurs in Mediterranean regions (den Herder et al. 2017). Agroforestry in this area is a complex assemblage of different land covers resulting from the activities of humankind over many millennia (Antrop 2004). Many of the traditional systems are 
recognised for their high natural and cultural value such as the dehesas in Spain, the montados in Portugal, and wood pastures in Sardinia, Italy. Agroforestry, with varying level of complexity, is also practised in intercropped or grazed olive orchards in Italy and Greece, where olive trees are often mixed with oak, carob, walnut, almond and other fruit trees (Eichhorn et al. 2006).

In many marginal rural areas, farmers believe that agroforestry is still the most appropriate land use as the poor quality of the land means that intensive monoculture systems are unsustainable. In these areas, trees have traditionally contributed to the rural economy through the production of fruits, fodder and wood for fuel, litter or timber (Mosquera-Losada et al. 2009, Rigueiro-Rodríguez et al. 2009). In addition, they have amenity value, provide shade and shelter for workers and livestock, and reduce erosion by wind and water (Palma et al. 2007, Reisner et al. 2007). Despite this, the composition and arrangement of Mediterranean agroforestry systems are significantly affected by urbanization, industrialization, logging, the EU's Common Agricultural Policy (CAP) and climate change (Simoniello et al. 2015).

European farmers recognise that agroforestry can provide environmental benefits (e.g. biodiversity conservation, carbon sequestration, soil erosion control, and landscape improvement) and increase production, diversify incomes, improve product quality, and provide business opportunities (Garcia de Jalon et al. 2017). However, at the same time, they perceive the complexity of agroforestry management (e.g. higher level of labour compared to monocultures, difficulty of mechanization) as a constraint (Camilli et al. 2016). The complexity of EU policy regarding agroforestry and the eligibility of such systems for Pillar I and II payments from the CAP can also discourage farmers. For example, trees in fields, rows and hedges could reduce Pillar I payments between 2007 and 2013 (Pisanelli et al. 2014). Despite some improvements in the current 2014-2020 round, the CAP can still undermine the practice of agroforestry (Mosquera-Losada et al. 2017).

Rois-Díaz et al. (2017) recently used farmer interviews to assess the factors determining the uptake of agroforestry. In the Mediterranean region, farmers reported that wild animals, such as wolves, were a problem and farmers were limiting the free-grazing of sheep to avoid attacks, with negative effects on the level and quality of meat and cheese production. Farmers reported that agroforestry products could be labelled or certified to compensate for higher costs. Mediterranean farmers, who do not currently practice agroforestry practices, also believe that agroforestry could play an important role in adapting to an increased incidence of extreme climate events such as heavy rainfall leading to flooding and landslides.

The aim of this research, undertaken alongside the study of Rois-Díaz et al. (2017), is to determine how different criteria affect uptake of alternative agroforestry practices in the Mediterranean region. In this research, quantitative inputs were obtained from agroforestry experts rather than qualitative inputs from farmers, and the results are generated through application of a multi-criteria decision making model (Analytic Network Process - ANP; Saaty, 1996) and not from the inductive analysis of interviews. The decision to start an agroforestry practice entails economic, social and environmental considerations and there are complex implications of possible benefits, costs, opportunities and risks. It can be very difficult to adequately present the relations between all these elements only by (essentially qualitative) input from farmers and different stakeholders. The novel use of an ANP model used in this study tackles this complexity through decision scenario focused on how a theoretical 'typical' farm for the Mediterranean region could improve its management system 
by implementing one of five alternative management options, namely: i) high natural and cultural value agroforestry systems, ii) agroforestry with high value trees, iii) agroforestry for arable systems, iv) agroforestry for livestock systems and v) no agroforestry.

\section{Material and methods}

Analytic Network Process (ANP; Saaty, 1996) is a generalization of the Analytic Hierarchy Process (AHP; Saaty, 1988). Both models are based on pairwise comparisons of its elements; but ANP has the benefit that any element of the model can be related to any other part of the model, whilst in AHP comparisons are done with respect to the element higher in its hierarchy. In this study an ANP model was developed with separate 'sub-models' (sub-matrices) for "benefits" (B), "opportunities" (O) , "costs" (C ) and "risks" (R). Benefits and costs entail criteria that are internal to the decision system and are focused on present, while opportunities and risks entail criteria that are external to the decision system and are focused on future. The decisions were based on a defined description of a situation and entailed a limited set of discrete alternative decisions.

Mathematically, the model is presented in the form of different matrices where all elements of the model are present both in rows and columns. The first and basic mathematical representation of the model is the 'unweighted supermatrix', in which the columns are the 'senders', and the rows are 'receivers' of the influence relation in the comparison of the model's elements (Saaty and Vargas 2006; Saaty 2008). This unweighted supermatrix can be separated into different symmetrical sections called components, describing different segments of the decision model. These components can be assigned with different weights, where the multiplication of the unweighted supermatrix with these weights produces a 'weighted supermatrix'. If the elements of the unweighted supermatrix are not separated into different components, then the unweighted supermatrix is the same as the weighted supermatrix. Multiplication of the weighted supermatrix by itself multiple times until the limit of the sum of all the powers of the matrix is reached (i.e. until all the columns are the same) yields the 'limit supermatrix'. The results of the model, i.e. the priorities of discrete alternatives, are stated in respective rows for each alternative in the limit supermatrix.

When the judgments, i.e. pairwise comparisons are made, they are stated in the form of a question. A classical form of a question would be: 'What is the relative importance/influence of the elements $A$ and $B$ ('sender' nodes) on element $C$ ('receiver' node)?' The answers would be presented in a textual form matching the Saaty's fundamental scale (ranging from 1 - equal importance to 9 extreme importance, where reciprocal values are used for inverse comparisons). Saaty (2008) discourages the use of values greater than 9 on the fundamental scale, as large numbers of possible elements in the comparison can lead to inconsistency of the scale's interpretation.

As indicated above, if two elements in a pairwise comparison are of equal importance, the selection value would be 1 , and both elements would be assigned with priority 0.5 . If one element is extremely more important than the other, then the selection would be 9 in favour of the dominant element. Their assigned priorities would be 0.9 for the dominant element, and 0.1 for the other one. For a model with multiple sub-matrices, overall priorities are calculated by relaying the respective BOCR priorities through a single formula. Commonly used formulas are either multiplicative $\left(B^{*} O / C^{*} R\right)$ or additive negative $\left(w^{*} B+w^{*} O-w^{*} C-w^{*} R\right)$. Saaty and Ozdemir (2005) report that the priorities obtained by multiplicative formula represent the best short-term results, and priorities obtained by additive negative formula represent the best long-term results. Other formulas for 
aggregation of overall priorities that are frequently used (Wijnmalen 2007) are multiplicative with weights as powers $\left(\left(B^{w} * O^{w}\right) /\left(C^{w *} R^{w}\right)\right)$, as also recommended by Saaty (2001), and additive with weights as coefficients $\left(w^{*} B+w^{*} O+w^{*} 1 / C+w^{*} 1 / R\right)$, where values of $1 / C$ and $1 / R$ are normalized to a 0-1 range. Linking the priority aggregation formulas to financial performance indicators, priorities attained through additive negative formula have analogies with a net cash flow, and priorities attained through additive formula with weights as coefficients have analogies with a net present value (Wijnmalen, 2007). All these formulas are used in this study, so that readers can relate priorities gained through different formulas to their divergent interpretations.

The fact that any element in ANP can be related to its any other part allows for modelling of feedback loops between its elements. The feedback loops are inherent in complex systems, and their modelling is the main reason why ANP was designed (Saaty, 2008). ANP was selected as the method for modelling possible uptake of agroforestry practices as such decisions encompass environmental, economic and social considerations, and feedback loops are one of the main characteristics of Human-Environment Systems (Scholz, 2011). In the agricultural and forestry sector, Jaafari et al. (2015) used ANP to select the best wood extraction method for forests in Northern Iran, García-Melón et al (2008) used it for farmland appraisal in Eastern Spain, Razavi-Toosi and Samani (2012) evaluated water transfer projects in the Karun River (Iran), and Wolfslehner et al. (2005) and Wolfslehner and Vacik (2008) assessed strategies for forest management in Austria. ANP can also be implemented in combination with other research approaches. For example Tran et al. (2004) combined ANP with a principal component analysis approach to rank threatened watersheds in the Mid-Atlantic Region of the United States. Catron et al. (2013) combined ANP with Strengths, Weaknesses, Opportunities and Threats (SWOT) to assess further development of biomass-based energy production, and Azimi et al. (2011) have used a similar approach to analyse mining strategies. ANP has been applied in hundreds of decision-making situations in a wide range of fields many of which are presented in three volumes of the Encyclicon (Saaty and Ozdemir, 2005; Saaty and Cillo, 2007; Saaty and Varas, 2011).

\section{Model design}

The ANP model was designed with the objective to assess the priorities of main types of agroforestry practices in the Mediterranean context within the framework of different economic, social and environmental criteria. Senior experts in agroforestry from Spain, Portugal, Italy and Greece were asked to describe a typical farm from their country and some farm management alternatives, which became the basis for the decision making models. The farm descriptions were refined and revised by the experts in a participatory manner several times to ensure convergence. The description of the farm and the alternative management scenarios are presented in Table 1. 
Table 1 Farm description and management alternatives of the ANP model

Description of the theoretical farm

The decision to adopt agroforestry practice or not is considered by a farmer which owns a farm in the Mediterranean region. The farm size is $200 \mathrm{ha}$, at an altitude between 0 and $600 \mathrm{~m}$, an annual precipitation of $500-660 \mathrm{~mm}$, average annual temperature of $11^{\circ} \mathrm{C}$ on cambisol soil with barley, wheat and alfalfa crops. A small forest ( $15 \mathrm{ha}$ ) of Quercus ilex belongs to the farm. Mechanization is possible due to the extensive flat lands. The owner is 55 years old, owns the farm, has low level educational qualifications, and currently implements traditional farming practices.

Management alternatives

1. Implement high natural and cultural value agroforestry system

The farmer considers adopting a high nature and cultural value agroforestry practice in these systems. The farmer considers including hedgerows and forest strips to promote biodiversity and an increase of crop resilience and adaptation to climate change. The chosen woody species are Quercus ilex and Juniperus thurifera.

2. Implement agroforestry with high value trees

The farmer considers adopting an agroforestry practice with high value trees. The farmer is looking for ways to increase the profitability of his farm and at the same time to improve ecosystem services. Part of the land will be planted with Prunus and Juglans trees (maximum of 100 trees per hectare to ensure the land remains eligible for CAP Pillar I payments). A management plan will be made with the objective to optimize high quality timber production. This will include a mid-term thinning of the stands, before final felling; pruning is done every year.

\section{Implement agroforestry for arable systems}

The farmer considers adopting an arable agroforestry system. The farmer is looking for ways to diversify farm production to ensure a more stable income base for the farm. The farmer decides to plant fast growing trees like poplar (Populus) in the arable land up to a maximum density of 100 trees per ha to ensure the land remains eligible for CAP Pillar I payments. The tree rows are planted at a spacing of $12 \mathrm{~m}$; along the rows the poplars are planted at $9 \mathrm{~m}$.

4. Implement agroforestry for livestock systems

The farmer considers adopting a livestock agroforestry system. The farmer is looking for ways to diversify farm production and is considering the combination of meat (lamb and beef), arable and forage crops to overcome season pasture deficits. Hedges of mulberry (Morus alba) trees with high quality forage value would be planted and sheep would be introduced in part of the arable land. Cattle will be introduced in the small forest of Quercus ilex. One large investment the farmer has to make is to fence the farm.

5. Do not implement agroforestry system

The farm continues on with the same management regime as before, and no changes are introduced.

Ten senior agroforestry experts were asked to define a preliminary list of social, environmental and economic criteria that might affect agroforestry implementation. These results were then presented and discussed in a workshop of the EU-sponsored AGFORWARD research project with 22 participants that were predominantly agroforestry scientists, but also with participation from agroforestry associations and agricultural advisory agencies. Each person filled-in another questionnaire where the list of criteria was improved and their relations were drafted. A draft ANP model was designed and sent back to the same group for comments in a form of a questionnaire. Subsequently, the improved model was send back again to the workshop participants to assign pairwise comparisons between the elements of the model. Respondents also commented on the importance of individual criteria, their meaning and potential overlap, and also on the general 
structure of the model. The main comment was that the model's complexity needed to be reduced. By eliminating the criteria that were mentioned by the lowest number of respondents, the number of criteria was reduced from 54 to 35 . Respondents received one last questionnaire which focused on 'critical' comparisons i.e. comparisons in which opinions of the respondents were divergent. The criterion for selection of a 'critical' comparison was that the priority vector value for at least one respondent diverged by at least 0.194 from the arithmetic mean of the priority, which is equal to sum of value of mean and of one standard deviation of the priority. The 'critical' comparison questionnaire comprised 26 out of a total of 73 direct comparisons in the model. Although 22 individuals participated in the first half of the model design, only eight respondents assigned pairwise comparisons between the elements of the model. For this reason, it would be prudent to state that the model was constructed with an input from eight decision makers - as this is a minimum number of people that have been involved in a single step of the model design.

After the last questionnaire, there were no more 'critical' judgments, and the design of the model was finalized (Figure 1), where the final values of the pairwise comparisons were based on the geometric mean of responses. At this point, calculation of final priorities and sensitivity analysis was performed. A summary of this analysis was given back to the respondents, and they were asked to provide their feedback, describing and commenting (both qualitatively and quantitatively on a Likert scale) to what extent the presented results were an adequate representation of a real-life situation. The final model is a full BOCR model with 35 criteria, where the benefits sub-network was further divided into three clusters representing environmental, economic and social benefits. The Benefits sub-network was assigned the highest weight (0.354), Costs and Risks had approximately same the weight (0.239 and 0.221), and Opportunities was given the smallest weighting (0.185).

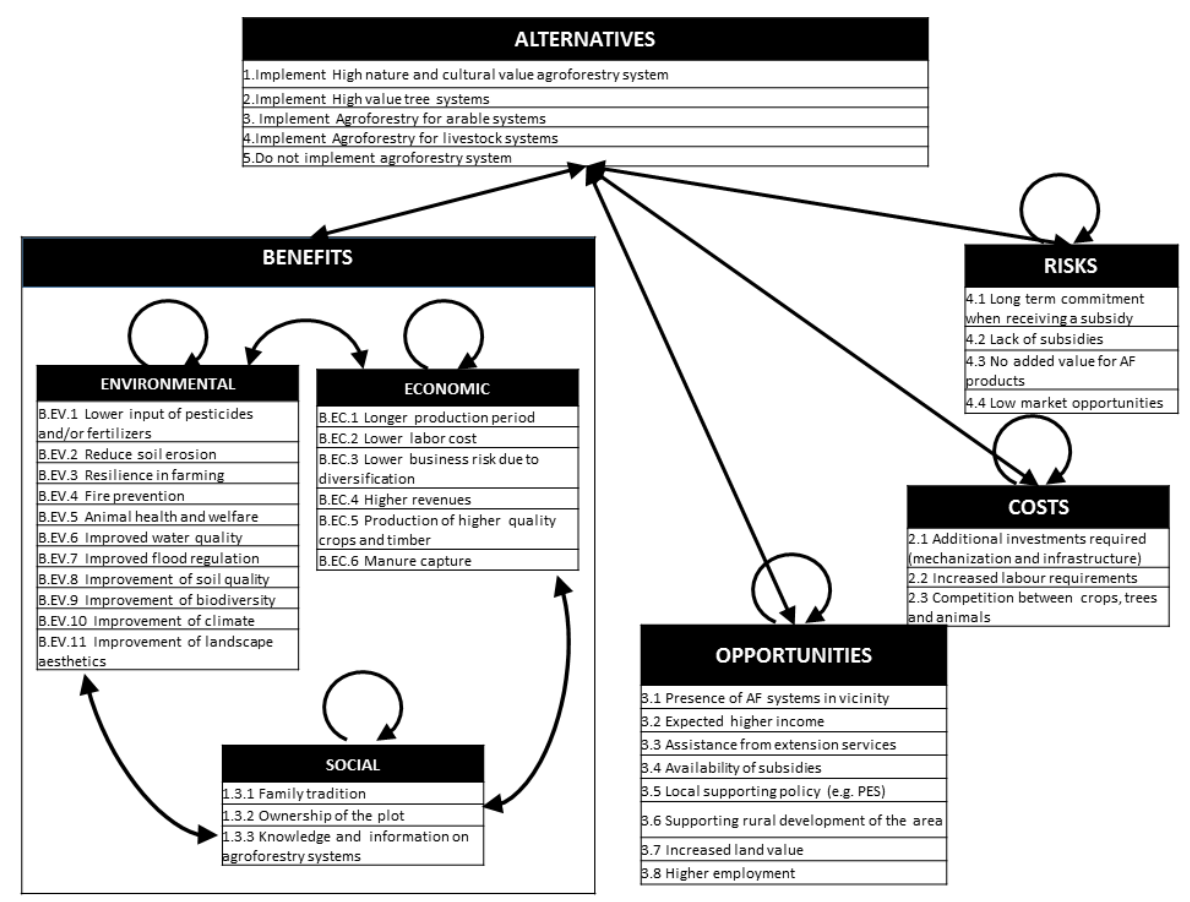

Fig. 1 The ANP model design examined five alternatives in terms of benefits, costs, opportunities, and risks. The benefits were considered within environmental, economic, and social areas 


\section{Results}

Selection of prioritisation formula

Although each of the four prioritisation formulas highlighted the high ranking of high nature and cultural value agroforestry, the relative ranking of the remaining four alternatives was affected by the choice of formula (Fig 2). The additive negative formula, which is reported to provide the best "long-term" results (Saaty and Ozdemir , 2005), resulted in much lower prioritisation of the other four alternatives compared to the other three formulas. In fact, with this method, no agroforestry (D5) had a negative priority. The prioritisation obtained with additive formula with weights as coefficients resulted in a minor change in ranking, as D4 (Implement agroforestry for livestock systems) has a marginally higher priority (0.991) than D2 (Implement agroforestry with high value trees; 0.933).

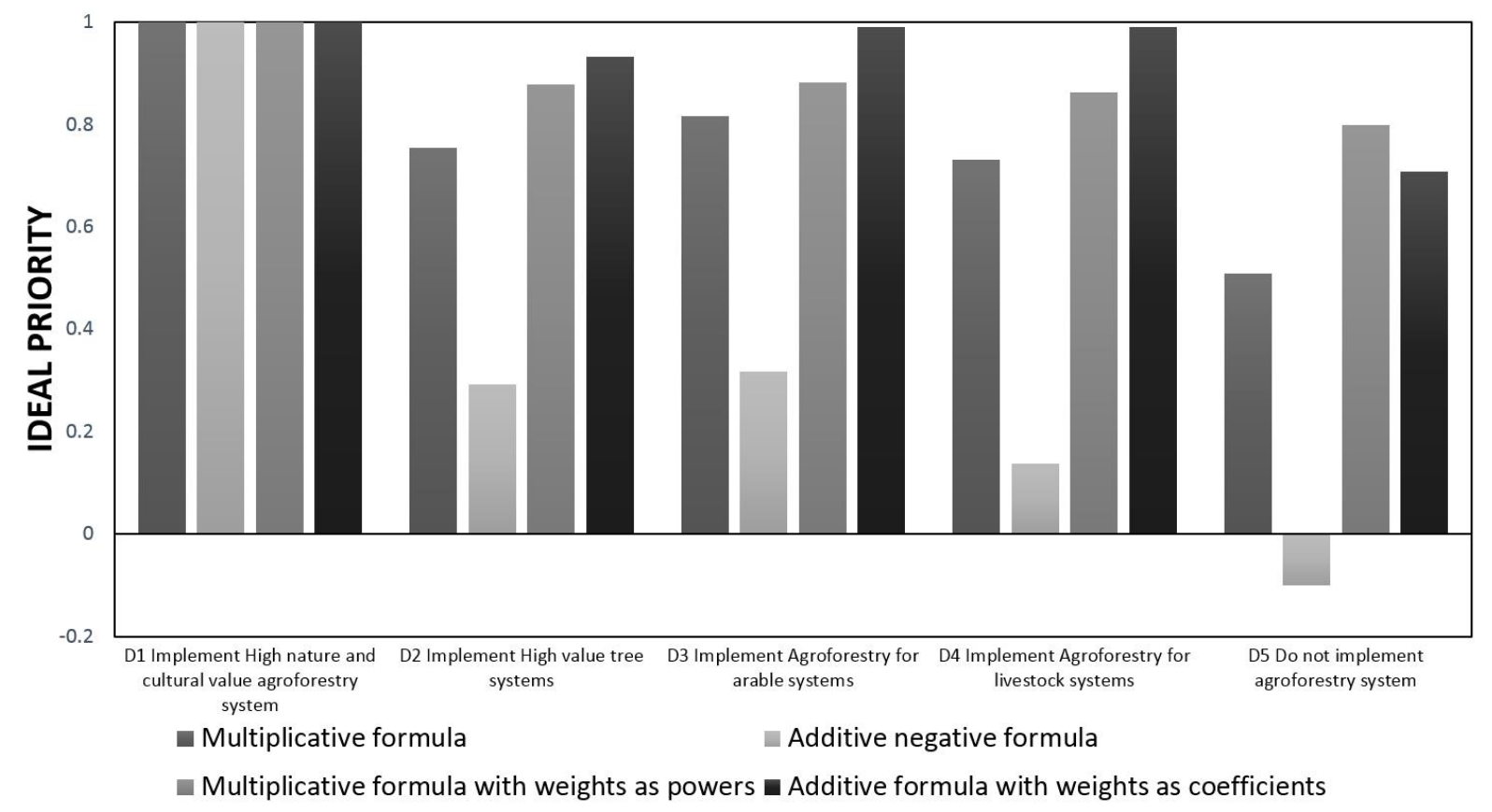

Fig. 2 The effect of four types of formulas for determining the balance of Benefits, Opportunities, Costs and Risks on describing five types of agroforestry decision in the Mediterranean region of Europe

Benefits, costs, opportunities, and risks

Figure 3 shows that both the benefits and opportunities associated with the decision to implement agroforestry (D1-D4) were greater than those with the decision to not implement agroforestry (D5). However the agroforestry systems were also associated with greater costs and risks. The greatest benefits were attributed to High natural and cultural value agroforestry systems (D1), which strongly contributed to the highest overall priority of this system. The low overall priority of Do not implement agroforestry (D5) does not stem from its low priority in individual sub-networks, but rather from the fact that the ratio of ideal priorities in the opportunities and risks sub-networks $(1: 2.72)$ is much more detrimental than is the case of other management alternatives $(1: 1.12,1: 0.86$, 1:0.67 and 1:0.68 for D1 to D4, respectively). 


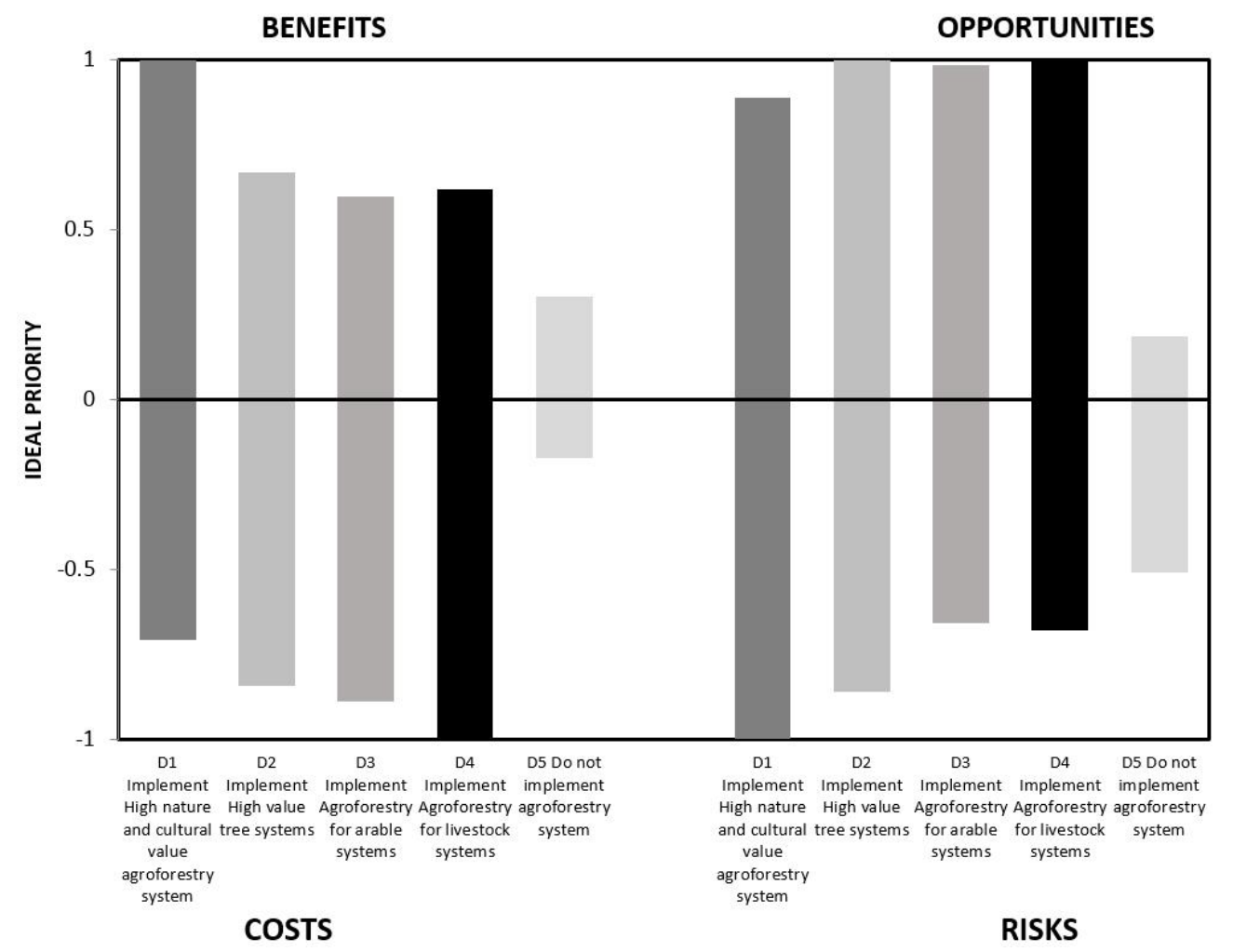

Fig. 3 BOCR ideal priorities for the ANP model

The main environmental benefit criteria in determining whether to implement agroforestry, as defined by the interviewed experts, were lower input of pesticides, improved water quality, and improved flood regulation (Table 2). In terms of economic benefits, the production of higher quality crops and timber and lower business risk due to diversification were prioritised. Knowledge and information on agroforestry systems and family tradition were the main social benefits. The main opportunity criteria were higher employment and availability of subsidies. The main cost criteria were increased labour requirements, and competition between crops, trees and animals. The main risk criteria were low market opportunities and lack of subsidies. 
Table 2. Priorities of criteria normalized by three benefit clusters, and cost, opportunity and risk cluster for determining the uptake of agroforestry in Mediterranean

\begin{tabular}{|c|c|c|}
\hline Cluster & Criterion & $\begin{array}{l}\text { Priority normalised } \\
\text { by cluster }\end{array}$ \\
\hline \multirow{11}{*}{$\begin{array}{l}\text { Environmental } \\
\text { benefits }\end{array}$} & Lower input of pesticides and/or fertilizers & 0.318 \\
\hline & Improved water quality & 0.246 \\
\hline & Improved flood regulation & 0.236 \\
\hline & Improvement of soil quality & 0.076 \\
\hline & Reduce soil erosion & 0.059 \\
\hline & Resilience in farming & 0.046 \\
\hline & Improvement of biodiversity & 0.014 \\
\hline & Animal health and welfare & 0.004 \\
\hline & Fire prevention & 0.001 \\
\hline & Improvement of climate & 0.000 \\
\hline & Improvement of landscape aesthetics & 0.000 \\
\hline \multirow{6}{*}{$\begin{array}{l}\text { Economic } \\
\text { benefits }\end{array}$} & Production of higher quality crops and timber & 0.455 \\
\hline & Lower business risk due to diversification & 0.452 \\
\hline & Longer production period & 0.045 \\
\hline & Lower labor cost & 0.025 \\
\hline & Manure capture & 0.019 \\
\hline & Higher revenues & 0.003 \\
\hline \multirow[t]{3}{*}{ Social benefits } & Knowledge and information on agroforestry systems & 0.552 \\
\hline & Family tradition & 0.423 \\
\hline & Ownership of the plot & 0.025 \\
\hline \multirow[t]{3}{*}{ Costs } & Increased labour requirements & 0.531 \\
\hline & Competition between crops, trees and animals & 0.469 \\
\hline & Additional investments required (mechanization and infrastructure) & 0.000 \\
\hline \multirow[t]{8}{*}{ Opportunities } & Availability of subsidies & 0.379 \\
\hline & Higher employment & 0.311 \\
\hline & Assistance from extension services & 0.241 \\
\hline & Local supporting policy (e.g. PES) & 0.040 \\
\hline & Presence of AF systems in vicinity & 0.028 \\
\hline & Expected higher income & 0.000 \\
\hline & Supporting rural development of the area & 0.000 \\
\hline & Increased land value & 0.000 \\
\hline \multirow[t]{4}{*}{ Risks } & Low market opportunities & 0.547 \\
\hline & Lack of subsidies & 0.453 \\
\hline & Long term commitment when receiving a subsidy & 0.000 \\
\hline & No added value for AF products & 0.000 \\
\hline
\end{tabular}

The priorities of criteria from the limit matrices of respective sub-networks have been normalized so that their sum in the respective cluster is 1 . Given the structure of the model, the cluster-level normalization is performed on the level of sub-networks for Costs, Opportunities and Risks, while for Benefits sub-network it is performed separately for three of its clusters.

Values above 0.2 are indicated in bold.

In order to test the robustness of the results, a sensitivity analysis was first performed on the level of sub-networks (Figure 4) using the additive negative formula. This sensitivity analysis shows increase of the priority of alternatives with increase of value of benefits and opportunities, and decrease of priorities to negative values with the increase in costs and risks. Although ranking of agroforestry management alternatives (D1-D4) show stability with the change of weights of the sub-networks, the same cannot be stated for No agroforestry (D5) alternative, as its relative priority (i.e. rank) increases with the decrease in the weight of Benefits and Opportunities, increases with the increase in the weight of Risks, and very strongly increases with the increase in the weight of Costs. 

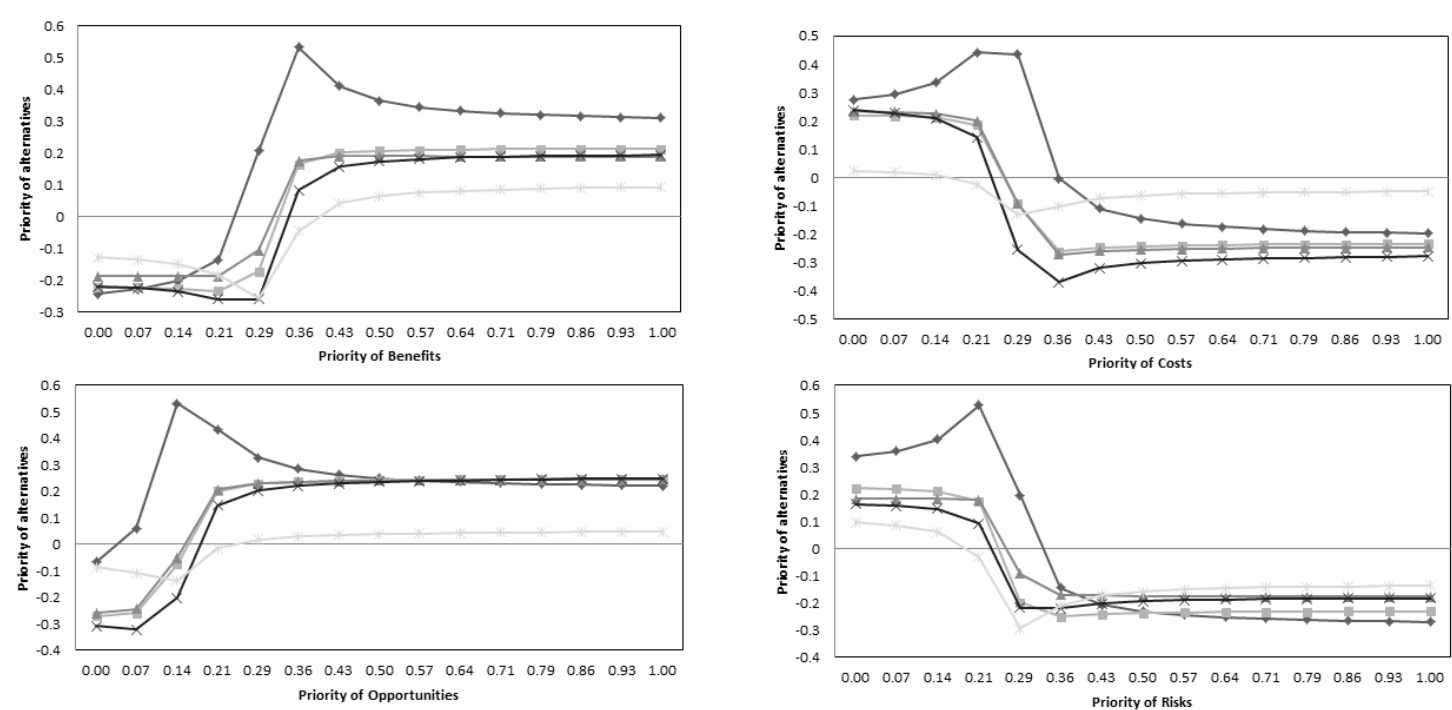

$$
\begin{aligned}
& -\mathrm{D} 1 \text { Implement High nature and cultural value agroforestry system }-\mathrm{D} 2 \text { Implement High value tree systems } \\
& -\mathrm{D} 3 \text { Implement Agroforestry for arable systems }
\end{aligned}
$$

Fig. 4 Sensitivity analysis of the prioritisation of four agroforestry decisions (D1-D4) and the decision to not implement agroforestry (D5) in terms of the Benefit, Opportunity, Costs, and Risk subnetworks using the additive negative formula

The next stage was to determine the sensitivity of prioritisation to five of the specific criteria, again using the additive negative formula. The node-level sensitivity graphs in Figure 5 are for the five criteria where the sensitivity analysis caused a change of ranking on the level of the respective subnetwork; and that has occurred for 5 out of 35 criteria, which indicates relative stability of priorities to the changing values of individual criteria.
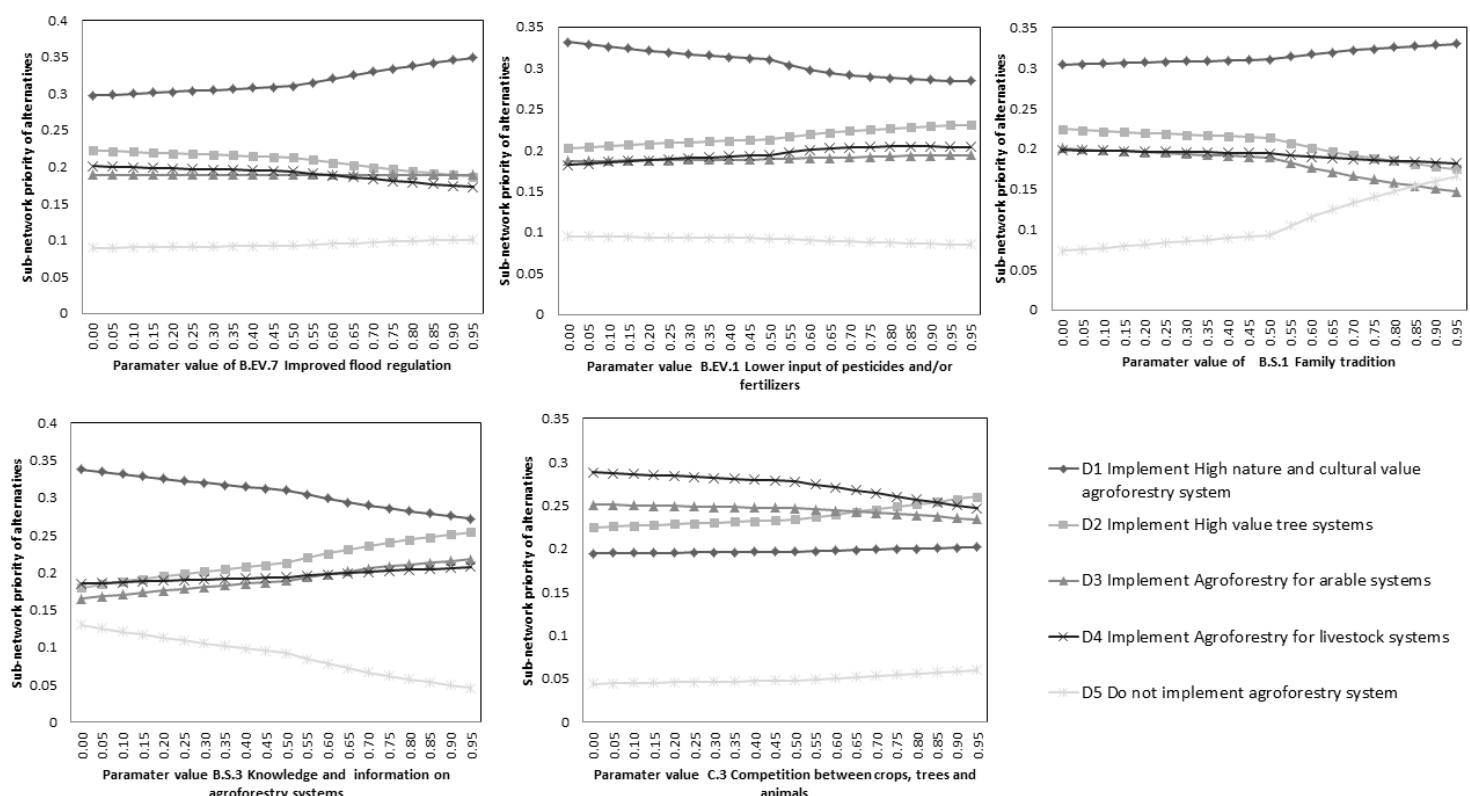

Fig. 5 Sensitivity analysis of the prioritisation of four agroforestry decisions (D1-D4) and the decision to not implement agroforestry (D5) in terms of five criteria: i) improved flood regulation, ii) lower inputs of pesticides and/or fertiliser, iii) family tradition, iv) knowledge and information on agroforestry systems, and v) competition between crops, trees and animals 
For the five selected individual criteria, the ranking between the implementation of agroforestry systems compared to no agroforestry was consistent, with no agroforestry (D1) only outranking the implementation of agroforestry for arable systems (D3) when a very high weighting is given to "family tradition" (Figure 5).

In the follow-up validation questionnaire respondents were given the results of the analysis, and asked 'Given your knowledge on agroforestry systems and with respect to the farm management scenarios, do you agree or not agree that the presented result is an adequate representation of a real-life situation?' This question was posed on a nine-point Likert scale, and asked separately for overall priorities under each aggregation formula, and separately for priorities under each subnetwork. The mean value of answer was 7.62, which falls under 'Strongly agree' category.

\section{Discussion}

\section{Prioritisation of agroforestry}

The ANP model, on the basis of the assumed weighting given to benefits, costs, opportunities and risks, gave the highest priority to High natural and cultural value agroforestry (D1) and a low overall priority to Do not implement agroforestry (D5). Novel practices such as agroforestry with high value trees (D2), and the selected practice of agroforestry for arable (D3) and livestock (D4) systems also received higher prioritisation than not implementing agroforestry (D5). These results are reflected in the large extent of high nature and cultural value agroforestry in European countries in the Mediterranean zone. Such regions generally have the largest coverage of agroforestry in Europe, ranging from $10.9 \%$ of the utilized agricultural area in Italy to about $40.9 \%$ in Cyprus (den Herder et al. 2016).

Our group of agroforestry experts perceived the most important environmental benefits as being a lower input of pesticides and fertilizers, improved water quality and improved flood regulation. By contrast the improvement of biodiversity, landscape aesthetics, soil conservation and animal welfare were given low priorities compared to those reported by Garcia de Jalón et al. (2017). The most important economic benefits were identified as lower business risk due to diversification and the production of higher quality crops and timber. This is consistent with the findings of Camilli et al. (2016, 2017), who reported that Italian farmers identified that the production of high quality products was one of the most important benefits of silvopastoral systems. It is also consistent with results on interviews with farmers reported by Rois-Díaz et al. (2017) who found that diversification of products, together with tradition and learning from others, was an important driver for the adoption of agroforestry.

Increased labour costs and competition between crops, trees, and animals were identified as the most significant costs determining the uptake of agroforestry (Table 2), mirroring the results of Sereke et al. (2014) and Camilli et al. (2016). The greatest opportunities were related to the availability of subsidies and assistance from extension services, and low market opportunities and lack of subsidies were seen as the greatest risks. Garcia de Jalón et al. (2017) in a pan-European study and Camilli et al. $(2016,2017)$ in a pan-Italian study also reported that the need for national demonstration sites and education programs to support the uptake of agroforestry. They cite the work of Pannell (1999) who identifies that a farmer considering agroforestry must i) have the information about the system, ii) be satisfied that it can be trialled, iii) perceive that it is worth 
trialling, and iv) and that it can support the objectives of the farm business, particularly profit. These conditions are not easily obtained in long-term systems such as agroforestry, in particular where the high initial investment costs are readily apparent and the full financial benefits may only be observed over a long period.

In the qualitative interviews with farmers reported by Rois-Díaz et al. (2017), it was noted that some farmers who implemented agroforestry were unfamiliar with the term "agroforestry". This lack of knowledge makes it difficult for a farmer to acknowledge the existence of the vast array of different criteria that are listed in the ANP model.

Rois-Díaz et al. (2017) reported on several variables behind uptake of agroforestry practices that were not included as criteria in the ANP model reported here. These were the age of the farmer (younger, rather than older, were more likely to implement agroforestry), income diversity (those with income from outside farming were more likely to implement), and tourism potential (farms with touristic potential were more likely to implement). A very similar approach to this study was taken by Camilli et al. (2017), where a comparable group of 'agroforestry stakeholders' (farmers, researchers, experts and policy makers) was asked on their perceptions on agroforestry in Italy, and where the feedback was generated through questionnaires administered in workshops, following a categorization of agroforestry systems that matches the decision alternatives in the ANP model of this study. Their study emphasized the importance of local supply chains for agroforestry products and management problems that might be caused by wild animals; issues that were not taken-up in this study. They also found that 'stakeholders' (mostly researchers), in comparison to farmers, have higher valued environmental aspects of agroforestry and downplayed the importance of management costs. However, on the overall range of descriptors of agroforestry, there was no statistically significant difference between the opinions of these two groups.

Robustness of results

The use of four different formulas for aggregation of overall priorities resulted in substantial changes in the ratio of the five alternative priorities (Figure 2). By contrast the ranking of the five decisions was generally robust across the four formulas (D1, D3, D2, D4 with D5 having the lowest priority), although the additive formula with weighting transposed the order of D2 and D4. The sensitivity analysis also showed a robustness of priorities to changes in the weighting to benefits, opportunities, costs or risks.

In general the implementation of high nature and value agroforestry (D1) was the prioritised land use and overall D5 (Do not implement agroforestry) received the lowest priority. Alternatives D2-D4 offer smaller benefits than D1 (the benefit sub-network is given a high weighting), moderately high costs and risks (which are sub-networks given a moderate weight), and although they offer high opportunities, the opportunity sub-network was given a low weighting. The negative overall priority of D5 is not a strange result as it has lowest priority attained through all other aggregation formulas, and additive negative formula is the only one in which a negative overall priority is possible. The wide range of priorities attained through additive negative formula is also an expected finding, as it follows other results found in the literature; e.g. in Wijnmalen (2007), range of normalized priorities obtained by multiplicative formula is 0.102 , from additive with reciprocals is 0.033 , and from additive negative is 0.826 . Saaty (2001) also states that multiplicative and additive outcomes may not always be close, and Saaty and $\mathrm{Hu}(10)$ demonstrate that they can have even different rankings. 
Any research design has limitations to the validity of its results and this study is no exception. Potential limitations include the bias of the respondents, the selection of the default farm type and alternatives, and respondent fatigue.

Respondent bias: within the final model, the weighting given to Benefits $(0.354)$ was greater than that to Costs (0.239), Risks (0.221) and Opportunities (0.185). The high weighting given to Benefits and the high benefit score for D1 (Figure 4) contributed to the high ranking of the High natural and cultural value agroforestry alternative. It could be argued that this result could be biased because it is based predominantly on input from agroforestry experts whom have intrinsic positive prejudice towards agroforestry. This threat is somewhat alleviated by the fact that results of this study show resemblance to findings of Rois-Díaz et al. (2017), a study with same objectives but one that is also based exclusively on farmer's input, including of those who do not implement agroforestry.

Selection of default farm type and alternatives: the reported results were developed with reference to the specified farm description and description of management alternatives, and not directly to the agroforestry in the Mediterranean region. We acknowledge that there cannot be a single farm description that is truly representative of the region, and this is the greatest validity issue of this study. We have designed the management scenario in a participatory manner, bearing in mind all the diversity that exists in agroforestry practised from Spain in the West to Greece in the East. However, this management scenario entails compromises between different viewpoints, approximations and inherently deviations from actual situation. For example, in the EU Farm Accountancy Data Network average farm size in the sample for seven listed Mediterranean countries is 29 ha with $5.5 \%$ of forests, while the farm in our description is about seven times bigger but it has similar (7.5\%) forest coverage.

Respondent fatigue: the ANP model was selected as multi-criteria decision model due to its ability to capture complexity; but this strength also has some drawbacks. The experts involved may have understood the general idea, the relations between the elements and the pairwise comparison. However, they did not fully understood the calculation process and thus how priorities are generated. Many rounds of discussion and questionnaires may have caused respondent fatigue, especially for the questionnaire in which they had to judge 73 pairwise comparisons. The AHP that was presented as a basis for ANP, on the other hand, was completely understood by respondents. The problems caused by selection of ANP as the decision method is somewhat alleviated by the fact that respondents strongly agree that the results of the model 'are an adequate representation of a real-life situation'.

\section{Conclusions}

This paper demonstrates that it was possible to develop an ANP model to describe the key considerations (from the perspective of experts) as to whether a farmer implements four alternative agroforestry systems, or no agroforestry, for a theoretical farm in Mediterranean Europe. This quantitative approach was undertaken alongside quantitative surveys of the main positive and negative attributes (Garcia de Jalon et al., 2017) and qualitative surveys on agroforestry (Rois-Díaz et al. 2017). Whilst it would be simpler to implement an AHP model, rather than an ANP model, in this study the ANP model was selected because it can allow a superior depiction of complexity. Our study showed that implementing an ANP model is a significant undertaking and the development of the model could have been simplified by limiting the number of criteria, which in turn would reduce the 
number of pairwise comparisons and the risk of respondent fatigue. Hence we would recommend that ANP is only used in situations with a limited number of respondents, where there is opportunity for substantial feedback between the modeller and the respondents, and where the respondents have sufficient interest in the model so that they can provide input without significant fatigue.

On the basis of the assumed weighting to benefits, opportunities, costs, and risks; the ANP model resulted in the highest prioritisation being given to high nature and cultural value agroforestry and the lowest prioritisation to no agroforestry. This result correlates well with the high coverage of high nature and cultural value agroforestry found in Mediterranean Europe. The model, based on the response of eight agroforestry experts, indicate that family tradition, product diversification, and lower use of pesticides are important determinants for the uptake of agroforestry. Similar results have been obtained from other surveys suggesting that the ANP methodology and the results are valid.

Because of the substantial iterations required, the model was developed using the responses from primarily agroforestry researchers rather than farmers. This may have resulted in a longer list of environmental compared to economic and social benefits (Table 2), but the exposure of agroforestry researchers to a wider range of systems, than many farmers, may allow them to appreciate the important decision making processes in different scenarios. Conversely the approach means that the personal attributes of the farmer or decision maker (e.g. age, land ownership, sources of other income) are not considered. Another positive aspect of this quantitative, structured approach is a dissemination of decision criteria between those which represent current status (i.e. benefits and costs) and those which represent the future (i.e. opportunities and risks). Sensitivity analysis clearly shows that the appeal of classical farming practices fades away in comparison to different agroforestry practices when opportunities are strengthened and risks are diminished. These futureoriented criteria that go beyond the scope of an individual farming scenario are the type of criteria that the policy sphere can affect in order to strengthen the uptake of agroforestry practices, i.e. by focusing on key opportunities and risks as identified in the ANP model, namely (i) providing framework that ensures availability of subsidies; (ii) providing adequate support from extension services and (iii) supporting agroforestry branding, labelling or certification schemes in order to tackle the issue of low market opportunities for its products.

\section{Acknowledgements}

This work was funded through the AGFORWARD Project from the European Union's Seventh Framework Programme for Research, Technological Development and Demonstration under Grant Agreement no. 613520. The authors would like to express their sincere gratitude to all the experts devoting their valuable time and knowledge to the questionnaires and feedback, and moreover for their input, which was essential for developing this study. 


\section{References}

Antrop M (2004) Landscape change and the urbanization process in Europe. Landsc. Urban. Plann., 67: 9-26.

Azimi R, Yazdani-Chamzini A, Fouladgar MM, Zavadskas EK, Basiri MH (2011) Ranking the strategies of mining sector through ANP and TOPSIS in a SWOT framework. Journal of Business Economics and Management 12, 670-689.

Camilli F, Pisanelli A, Seddaiu G, Franca A, Bondesan V, Rosati A, Moreno GM, Pantera A, Hermansen JE, Burgess PJ (2016) Benefits and constraints associated to agroforestry systems: the case studies implemented in Italy within the Agforward project. Book of abstracts of the 3nd EURAF Conference, Montpellier SupAgro, France, pp. 19-22.

Camilli F, Pisanelli A, Seddaiu G, Franca A, Bondesan V, Rosati A, Moreno GM, Pantera A, Hermansen JE, Burgess PJ (2017) How local stakeholders perceive agroforestry systems: an Italian perspective. Agroforest Syst 1-14. doi:10.1007/s10457-017-0127-0

Catron J, Stainback GA, Dwivedi P, Lhotka JM (2013) Bioenergy development in Kentucky: A SWOTANP analysis. Forest Policy and Economics 28, 38-43.

den Herder M, Moreno G, Mosquera-Losada MR, Palma JHN, Sidiropoulou A, Santiago-Freijanes J, Crous-Duran J, Paulo J, Tomé M, Pantera A, Papanastasis V, Mantzanas K, Pachana P, Papadopoulos A, Plieninger T, Burgess PJ (2016) Current extent and trends of agroforestry in the EU27. Deliverable Report 1.2 for EU FP7 Research Project: AGFORWARD 613520. (15 August 2016). 2nd Edition. 76 pp. http://agforward.eu/index.php/en/current-extent-andtrends-of-agroforestry-in-the-eu27.html. Accessed 09 January 2017

den Herder M, Moreno G, Mosquera-Losada RM, Palma JHN, Sidiropoulou A, Santiago-Freijanes JJ, Crous-Duran J, Paulo JA, Tomé M, Pantera A, Papanastasis VP, Mantzanas K, Pachana P, Papadopoulos A, Plieninger T, Burgess PJ (2017) Current extent and stratification of agroforestry in the European Union. Agriculture, Ecosystems \& Environment 241, 121-132. doi:10.1016/j.agee.2017.03.005

Eichhorn MP, Paris P, Herzog F, Incoll LD, Liagre F, Mantzanas K, Mayus M, Moreno G, Papanastasis VP, Pilbeam DJ, Pisanelli A, Dupraz C (2006) Silvoarable Systems in Europe: past, present and future prospects. Agroforestry Systems, 67:29-50.

García-Melón M, Ferrís-Oñate J, Aznar-Bellver J, Aragonés-Beltrán P, Poveda-Bautista R (2008) Farmland appraisal based on the analytic network process. Journal of Global Optimization, 42(2), pp.143-155.

Graves AR, Burgess PJ, Liagre F, Pisanelli A, Paris P, Moreno G, Bellido M, Mayus M, Postma M, Schidler B, Mantzanas K, Papanastasis VP, Dupraz, C (2008) Farmer perceptions of silvoarable systems in seven European countries. Advances in Agroforestry 6: 67-86

Jaafari A, Najafi A, García-Melón M (2015) Decision-making for the selection of a best wood extraction method: An analytic network process approach Forest Policy and Economics 50. 200-209.

Jalón SG, Burgess PJ, Graves A, Moreno G, McAdam J, Pottier E, Novak S, Bondesan V, MosqueraLosada R, Crous-Durán J, Palma JHN, Paulo JA, Oliveira TS, Cirou E, Hannachi Y, Pantera A, Wartelle R, Kay S, Malignier N, Lerberghe PV, Tsonkova P, Mirck J, Rois M, Kongsted AG, Thenail C, Luske B, Berg S, Gosme M, Vityi A (2017) How is agroforestry perceived in Europe? An assessment of positive and negative aspects by stakeholders. Agroforest Syst 1-20. doi:10.1007/s10457-017-0116-3 
Luske B, van Veluw K, Vonk M (2016) Bottlenecks and solutions for introducing agroforestry: A case study for the Netherlands. Book of abstracts of the 3rd European Agroforestry Conference, 23-25 May 2016 - Montpellier, France, pp. 27-29.

Mosquera-Losada MR, McAdam J, Romero-Franco R, Santiago-Freijanes JJ, Riguero-Rodríquez A (2009) Definitions and components of agroforestry practices in Europe. In: RigueiroRodríguez, A., McAdam, J., Mosquera-Losado, M. (Eds.), Agroforestry in Europe: Current Status and Future Prospects. Springer Science + Business Media B.V., Dordrecht, pp. 3-19.

Mosquera-Losada MR, Santiago Freijanes JJ., Pisanelli A, Rois M, Smith J, den Herder M, Moreno G, Lamersdorf N, Ferreiro-Domínguez N, Balaguer F, Pantera A, Papanastasis V, RigueiroRodríguez A, Aldrey JA, Gonzalez-Hernández P, Fernández-Lorenzo JL, Romero-Franco R, Lampkin N, Burgess PJ (2017) Deliverable 8.24: How can policy support the appropriate development and uptake of agroforestry in Europe? September 2017. 21 pp. URL: https://agforward.eu/index.php/en/how-can-policy-support-the-uptake-of-agroforestry-ineurope.html.

Palma J, Graves A, Bunce R, Burgess P, De Filippi R, Keesman K, van Keulen H, Mayus M, Reisner Y, Liagre F, Moreno G, Herzog F (2007) Modelling environmental benefits of silvoarable agroforestry in Europe. Agric. Ecosyst. Environ. 119 (3-4), 320-334.

Pannell DJ (1999) Social and Economic Challenges to the Development of Complex Farming Systems. SEA Working Paper 97/02. Sustainability and Economics in Agriculture.

Pisanelli A, Marandola D, Marongiu S, Paris P, Rosati A, Romano R (2014) The role of development policy in supporting agroforestry systems in EU. Book of abstracts of the 2nd EURAF Conference, Cottbus (Germany) 4-6 June 2014, pp. 22-25. ISBN: 978-972-97874-4-7

Razavi-Toosi SL, Samani JMV (2012) Evaluating water transfer projects using analytic network process (ANP). Water Resources Management. 26:1999-2014

Reisner Y, De Filippi R, Herzog F, Palma J (2007) Target regions for silvoarable agroforestry in Europe. Ecol. Eng. 29, 401-418.

Rigueiro-Rodríguez A, Fernández-Núñez E, González-Hernández MP, McAdam JH, Mosquera-Losada MR (2009) Agroforestry in Europe: Current Status and Future Prospects. Springer

Rois-Díaz M, Lovric N, Lovric M, Ferreiro-Domínguez N, Mosquera-Losada MR, den Herder M, Graves A, Palma J, Paulo JA, Pisanelli A, Smith J, Moreno G, García S, Varga A, Pantera A, Mirck J, Burgess $P$ (2017) Farmers' reasoning behind the uptake of agroforestry practices: evidence from multiple case-studies across Europe. Agroforestry Systems. 1-18.

Saaty TL (1988) What is the analytic hierarchy process? In: Mathematical models for decision support (pp. 109-121). Springer, Berlin, Heidelberg.

Saaty TL (1996) Decision making with dependence and feedback: The analytic network process (Vol. 4922). Pittsburgh: RWS publications.

Saaty TL (2001) The seven pillars of the analytic hierarchy process. In Multiple Criteria Decision Making in the New Millennium (pp. 15-37). Springer, Berlin, Heidelberg.

Saaty TL (2008) Decision making with the analytic hierarchy process. International journal of services sciences 1 (1), 83-98.

Saaty TL, Cillo B (2007) The Encyclicon, Volume 2: A Dictionary of Complex Decisions Using the Analytic Network Process. RWS Publications, Pittsburgh, 365p.

Saaty TL, Hu G (1998) Ranking by eigenvector versus other methods in the analytic hierarchy process. Applied Mathematics Letters, 11(4), pp.121-125. 
Saaty TL, Ozdemir MS (2005) The Encyclicon: A Dictionary of Decisions with Dependence and Feedback Based on the Analytic Network Process. RWS Publications, Pittsburg

Saaty TL, Vargas LG (2006) Uncertainty and rank order in the analytic hierarchy process. European Journal of Operational Research 32 (1), 107-117

Saaty TL, Vargas LG (2011) The Encyclicon, Volume 3: A Dictionary of Complex Decisions Using the Analytic Network Process. RWS Publications, Pittsburgh, 298p.

Scholz RW (2011) Environmental literacy in science and society: from knowledge to decisions. Cambridge University Press.

Sereke F, Graves A, Dux D, Palma J, Herzog F (2015) Innovative agroecosystem goods and services: key profitability drivers in Swiss agroforestry. Agronomy for Sustainable Development, 35(2), 759 - 770. DOI: 10.1007/s13593-014-0261-2

Simoniello T, Coluzzi R, Imbrenda V, Lanfredi M (2015) Land cover changes and forest landscape evolution (1985-2009) in a typical Mediterranean agroforestry system (high Agri Valley). Nat. Hazards Earth Syst. Sci., 15, 1201-1214.

Smith J (2010) The history of temperate agroforestry. Organic Research Centre, Elm Farm, Newbury, Berkshire, UK, $17 \mathrm{pp}$

Tran LT, Knight CG, O'Neill RV, Smith ER (2004) Integrated environmental assessment of the MidAtlantic Region with analytical network process. Environmental Monitoring and Assessment 94, 263-277.

Wijnmalen WJD (2007) Analysis of benefits, opportunities, costs, and risks (BOCR) with the AHPANP: A critical validation. Mathematical and Computer Modelling 46, 892-90

Wolfslehner B, Vacik H (2008) Evaluating sustainable forest management strategies with the Analytic Network Process in a Pressure-State-Response framework. Journal of Environmental Management 88. 1-10

Wolfslehner B, Vacik H, Lexer MJ, Wurz A, Hochbichler E, Klumpp R, Spork J (2003) A system analysis approach for assessing sustainable forest management at FMU level. FAO Forestry Department: XII World Forestry Congress-Forest's Source of Life, September 21-28th, Quebec, /http://www.fao.org/DOCREP/ARTICLE/ WFC/XII/0690-B4.HTMS 